(2) Open Access Full Text Article

\title{
Intraocular pressure in Japanese diabetic patients
}

This article was published in the following Dove Press journal:

Clinical Ophthalmology

30 June 2012

Number of times this article has been viewed

\section{Masato Matsuoka'}

Nahoko Ogata ${ }^{2}$

Kayako Matsuyama'

Tadanobu Yoshikawa'

Kanji Takahashi ${ }^{3}$

'Department of Ophthalmology,

Kansai Medical University, Takii

Hospital, Osaka, ${ }^{2}$ Department

of Ophthalmology, Nara Medical

University, Nara, ${ }^{3}$ Department of

Ophthalmology, Kansai Medical

University, Hirakata Hospital,

Osaka, Japan
Correspondence: Nahoko Ogata Department of Ophthalmology, Nara Medical University, 840 Shijo-cho, Kashihara, Nara 634-8522, Japan

Tel +81744298884

Fax +81744238032

Email ogata@takii.kmu.ac.jp
Background: To determine whether the intraocular pressure (IOP) in diabetic patients is significantly different from that in nondiabetic patients.

Methods: The medical records of all patients who were initially examined in the Department of Ophthalmology, Kansai Medical University, Takii Hospital were reviewed. At the initial examination, patients had a detailed interview and underwent a comprehensive ophthalmic examinations. All patients were over 20 years of age and did not have glaucoma.

Results: A total of 703 patients were evaluated. The mean ( \pm standard error) IOP of the diabetic patients was $15.5 \pm 0.2 \mathrm{mmHg}(\mathrm{n}=206)$, and was significantly higher than the $14.0 \pm 0.1 \mathrm{mmHg}$ $(\mathrm{n}=497)$ in the nondiabetic patients $(P<0.0001)$. The IOP was negatively correlated with age $(\mathrm{r}=-0.202 ; P=0.024)$ in the diabetic patients and was weakly but significantly correlated with the glycosylated hemoglobin $\left(\mathrm{HbA}_{1 \mathrm{c}}\right)$ level $(\mathrm{r}=0.240 ; P=0.015)$ in the group with diabetic retinopathy.

Conclusion: The significantly higher IOP in diabetic patients and positive correlation of IOP with $\mathrm{HbA}_{1 \mathrm{c}}$ levels in patients with diabetic retinopathy indicate that IOP in diabetic patients is higher, especially in those with poor control of diabetes.

Keywords: diabetes mellitus, diabetic retinopathy, intraocular pressure, open-angle glaucoma

\section{Introduction}

Diabetes mellitus is a major public health problem, and a marked increase in the disease burden is projected by $2025 .{ }^{1}$ Diabetic retinopathy is a serious microvascular complication of diabetes mellitus and is a major cause of adult blindness. Relevant to this study, several cross-sectional studies have found a positive correlation between diabetes and primary open-angle glaucoma. ${ }^{2-6}$ However, there have been other studies that failed to confirm this association. ${ }^{7-13}$ Thus, the relationship between diabetes mellitus and open-angle glaucoma has not been established.

Several population-based studies have consistently reported that intraocular pressure (IOP) is significantly higher in subjects with diabetes than in those without diabetes, ${ }^{2-7,9,10,12,14,15}$ although some of them failed to find a positive correlation between diabetes and open-angle glaucoma. ${ }^{7,9,10}$ The Japanese population-based Tajimi study reported that diabetic patients had significantly higher IOP, but the presence of diabetes was not significantly associated with the development of open-angle glaucoma. ${ }^{16,17}$ However, only limited data exist on the relationship between diabetes mellitus and IOP in the Japanese population, and earlier studies have not evaluated diabetic status, such as the glycosylated hemoglobin $\left(\mathrm{HbA}_{\mathrm{lc}}\right)$ level, and the effect of degree of diabetic retinopathy on IOP. ${ }^{16,17}$ 
Thus, the purpose of this study was to determine whether a significant correlation exists between IOP and diabetes, the degree of diabetic retinopathy, and the $\mathrm{HbA}_{1 \mathrm{c}}$ level. To accomplish this, we examined the IOP of patients with diabetes mellitus and compared their IOP with that in subjects without diabetes mellitus.

\section{Materials and methods}

\section{Participants}

The procedures used in this study conformed to the tenets of the Declaration of Helsinki. The medical records of all patients who first visited the Department of Ophthalmology, Kansai Medical University Takii Hospital (Osaka, Japan) between April 2008 and July 2009 were reviewed. At the initial examination, all patients were interviewed regarding their medical history, including past ocular diseases. Patients who underwent a standard ophthalmic examination, including determination of visual acuity, refraction, slitlamp examination, and fundus examination were included in this study.

IOP was measured routinely three times with a noncontact tonometer (Topcon CT90, Topcon, Tokyo, Japan), and the average of the right eye was used for the statistical analyses. Patients who were $<20$ years old, had corneal disease, uveitis, ocular inflammatory disease, and fundus diseases except for diabetic retinopathy were excluded. In addition, patients who had undergone any intraocular surgery, eg, for cataract, vitrectomy, glaucoma, or buckling surgery, were excluded. However, patients with mild cataracts in whom the fundus could be examined were included. Patients with definite glaucoma, suspected glaucoma, ${ }^{9,16,17}$ or other types of glaucoma, including neovascular glaucoma, and those who were receiving IOP-lowering treatments were excluded. $\mathrm{HbA}_{1 \mathrm{c}}$ levels determined by standard laboratory procedures were obtained from medical records.

\section{Classification of diabetic retinopathy}

All patients included in this study underwent a standard ophthalmic examination at the initial visit. The stage of diabetic retinopathy was determined by ophthalmoscopy and fluorescein angiography. The patients were classified according to the severity of diabetic retinopathy; ie, no apparent diabetic retinopathy, mild to moderate nonproliferative diabetic retinopathy, severe nonproliferative diabetic retinopathy, and proliferative diabetic retinopathy. ${ }^{18}$ Patients identified to have proliferative diabetic retinopathy underwent routine gonioscopy to exclude neovascular glaucoma. The association between IOP and the presence or absence of diabetes mellitus, gender, age, stage of diabetic retinopathy, and $\mathrm{HbA}_{1 \mathrm{c}}$ level were evaluated.

\section{Statistical analyses}

The results are expressed as the mean \pm standard error of the mean (SEM), and the data were analyzed statistically using the Mann-Whitney test and one-way analysis of variance with Dunnett's correction when comparing groups. Associations between the parameters were examined by Pearson's product moment correlation coefficients ( $\mathrm{r}$ ). The statistical analysis package SPSS 14.0 for Windows (SPSS Inc, Chicago, IL) was used for statistical processing. A $P$ value $<0.05$ was accepted as significant.

\section{Results}

Of the 703 patients, 206 were diagnosed with diabetes and 497 without diabetes. The mean ( \pm standard deviation) age of the 206 diabetic patients was $61.4 \pm 11.9$ years with a range of 21 to 85 years. The 206 diabetic patients included 140 men (age $60.6 \pm 10.8$ years) and 66 women (age $63.2 \pm 13.9$ years). The mean age of the 497 nondiabetic patients was $61.7 \pm 15.6$ years with a range from 21 to 95 years. The 497 nondiabetic patients included 210 men (age 58.8 \pm 16.2 years) and 287 women (age $63.9 \pm 14.8$ years $)$.

The mean $( \pm \mathrm{SEM}) \mathrm{IOP}$ was $14.0 \pm 0.12 \mathrm{mmHg}$ in the nondiabetic group and $15.5 \pm 0.24 \mathrm{mmHg}$ in the diabetic group (Figure 1). The IOP in the diabetic patients was significantly higher than that in the nondiabetic patients $(P<0.0001$, Mann-Whitney test $)$.

In the nondiabetic group, the mean IOP was $13.9 \pm$ $0.2 \mathrm{mmHg}$ in men $(\mathrm{n}=210)$ and $14.2 \pm 0.36 \mathrm{mmHg}$ in women $(\mathrm{n}=287)$; in the diabetic group, the mean IOP was $15.4 \pm 0.27 \mathrm{mmHg}$ in men $(\mathrm{n}=140)$ and $15.8 \pm 0.46 \mathrm{mmHg}$ in women $(n=66$, Figure 2$)$. Differences in IOP between

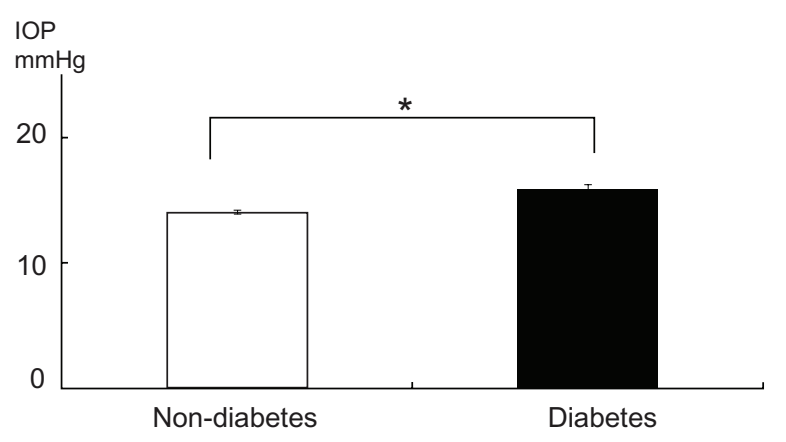

Figure I IOP in patients with and without diabetes.

Notes: The mean IOP was $14.0 \pm 0.1 \mathrm{mmHg}$ in the nondiabetes group $(n=497)$ and $15.5 \pm 0.2 \mathrm{mmHg}$ in the diabetes group $(n=206)$. The IOP in the diabetic patients was significantly higher than that in nondiabetic patients. ${ }^{*} P<0.0001$.

Abbreviation: IOP, intraocular pressure. 


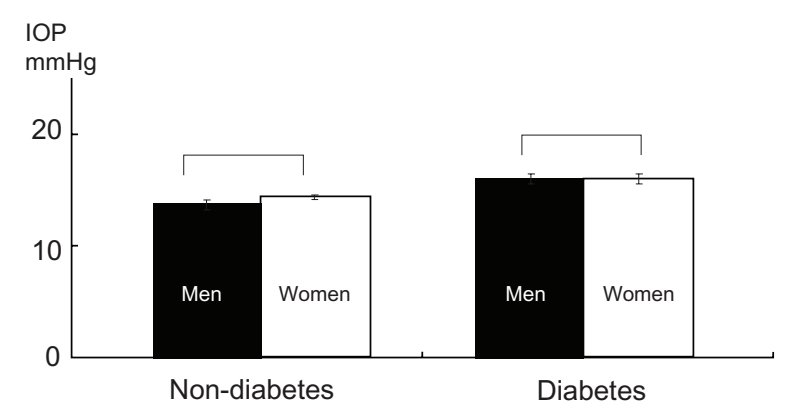

Figure 2 Effect of gender on IOP.

Notes: In the nondiabetes group, mean IOP was $13.9 \pm 0.2 \mathrm{mmHg}$ in men $(n=210)$ and $14.2 \pm 0.4 \mathrm{mmHg}$ in women $(\mathrm{n}=287)$. In the diabetic group, mean IOP was $15.4 \pm 0.27 \mathrm{mmHg}$ in men $(n=140)$ and $15.8 \pm 0.46 \mathrm{mmHg}$ in women $(n=66)$. Differences in IOP between men and women were not significant in either group ( $P=0.17$ in the nondiabetes group, $P=0.64$ in the diabetes group).

Abbreviation: IOP, intraocular pressure.

the men and women in both groups were not significant ( $P=0.17$ in nondiabetic group, $P=0.64$ in diabetes group, Mann-Whitney test).

The IOP was $15.6 \pm 0.4 \mathrm{mmHg}$ in patients with no apparent diabetic retinopathy $(n=95$, age $61.1 \pm 13.4$ years $)$, $15.7 \pm 0.5 \mathrm{mmHg}$ in patients with mild to moderate nonproliferative diabetic retinopathy $(n=46,65.8 \pm 9.16$ years $)$, $15.0 \pm 0.5 \mathrm{mmHg}$ in patients with severe nonproliferative diabetic retinopathy $(n=41,60.2 \pm 10.8$ years), and $18.0 \pm 2.2 \mathrm{mmHg}$ in patients with proliferative diabetic retinopathy $(n=24,56.9 \pm 9.19$ years, Figure 3$)$. The IOP in each diabetic retinopathy group was significantly higher than that in the nondiabetic group $(P<0.001$, one-way analysis of variance with Dunnett's test) but there was no significant difference between the diabetic retinopathy groups.

The IOP decreased significantly with increasing age in the diabetic patients, and a calculation of Pearson's product

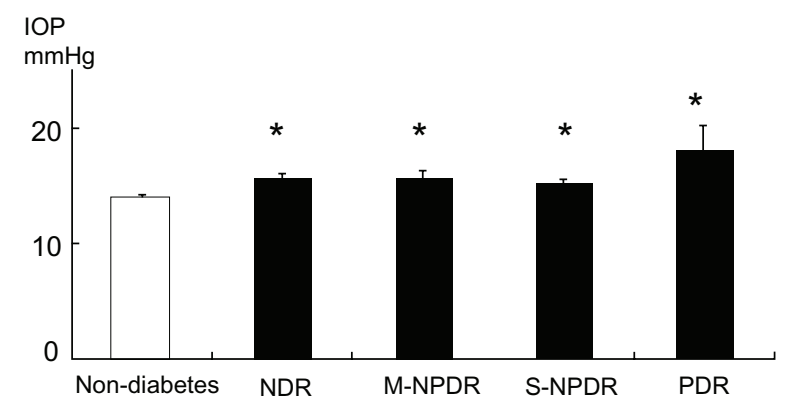

Figure 3 Effect of progression of diabetic retinopathy on IOP.

Notes: IOP was $15.6 \pm 0.4 \mathrm{mmHg}$ in patients with NDR $(\mathrm{n}=95), 15.7 \pm 0.5 \mathrm{mmHg}$ in M-NPDR $(n=46), 15.0 \pm 0.5 \mathrm{mmHg}$ in S-NPDR $(n=41)$, and $18.0 \pm 2.2 \mathrm{mmHg}$ in PDR $(n=24)$. The IOP in each diabetic retinopathy group was significantly higher than that in their nondiabetic group $(P<0.00 \mathrm{I})$, but there was no significant difference between the diabetic retinopathy groups. $* P<0.001$.

Abbreviations: IOP, intraocular pressure; NDR, no apparent diabetic retinopathy; M-NPDR, mild to moderate nonproliferative diabetic retinopathy; S-NPDR, severe nonproliferative diabetic retinopathy; PDR, proliferative diabetic retinopathy. moment correlation coefficient ( $r$ ) between IOP and age showed that the correlation was significant $(r=-0.202$, $P=0.024, \mathrm{n}=206$, Figure 4). The IOP also decreased with increasing age in the nondiabetic group but the decrease was not significant ( $\mathrm{r}=-0.07, P=0.12, \mathrm{n}=497$ ).

The IOP of diabetic patients increased with increasing $\mathrm{HbA}_{1 \mathrm{c}}$ but the correlation was not significant $(\mathrm{r}=0.142$, $P=0.058, \mathrm{n}=179$ ). When we examined the IOP of patients with diabetic retinopathy (patients with mild to moderate nonproliferative diabetic retinopathy, severe nonproliferative diabetic retinopathy, and proliferative diabetic retinopathy), there was a significant correlation between IOP and $\mathrm{HbA}_{1 \mathrm{c}}$ level $(\mathrm{r}=0.240, P=0.015, \mathrm{n}=102$, Figure 5).

\section{Discussion}

Both glaucoma and diabetic retinopathy are leading causes of irreversible blindness worldwide. ${ }^{19,20}$ Diabetes mellitus is known to cause microvascular damage and may affect the autoregulatory action of the blood vessels in the retina and optic nerve. Diabetes has been found to be associated with elevated IOP and has therefore been suggested to be a possible risk factor for glaucoma, particularly open-angle glaucoma. ${ }^{2-6}$

However, the evidence to support this relationship remains inconsistent. The Baltimore Eye Survey ${ }^{7}$ and some other studies ${ }^{10,16}$ reported that diabetes was significantly associated with higher IOP but not with the development of open-angle glaucoma. In addition, the recent Beijing Eye study ${ }^{9}$ reported that ocular hypertension was significantly associated with diabetes as assessed independently in multivariate analysis but the prevalence of glaucomatous optic nerve damage was not associated with diabetes.

The gold standard for the measurement of IOP is the Goldmann applanation tonometer. However, IOP by

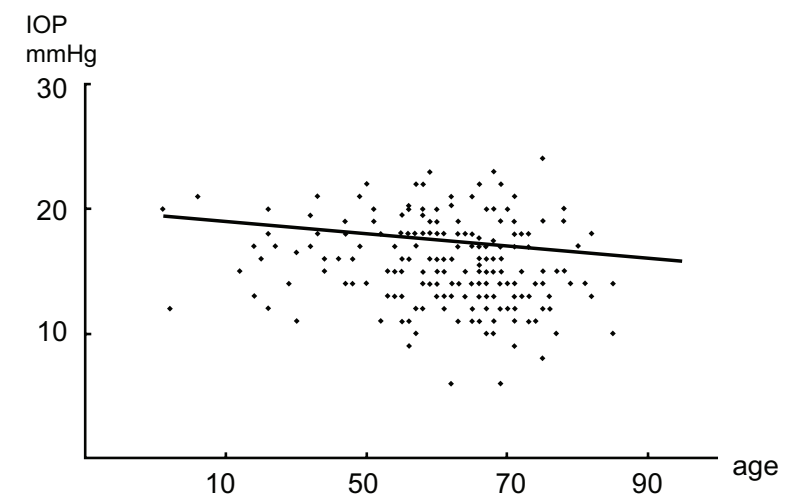

Figure 4 Effect of age on IOP in diabetic patients.

Notes: IOP decreased significantly with increasing age in diabetic patients $(\mathrm{r}=-0.202, P=0.024, \mathrm{n}=206)$

Abbreviation: IOP, intraocular pressure. 


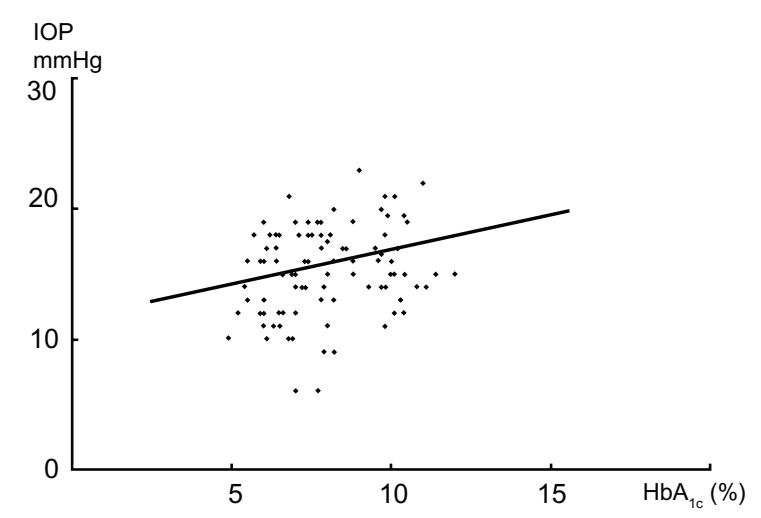

Figure 5 IOP and $\mathrm{HbA}_{\mathrm{lc}}$ in patients with diabetic retinopathy. Notes: IOP and $\mathrm{HbA}_{\mathrm{lc}}$ of patients with diabetic retinopathy (patients with M-NPDR, S-NPDR, and PDR) were significantly correlated $(r=0.240, P=0.015, n=102)$. Abbreviations: IOP, intraocular pressure; $\mathrm{HbA}_{\mathrm{lc}}$, glycosylated hemoglobin; M-NPDR, mild to moderate nonproliferative diabetic retinopathy; S-NPDR, severe nonproliferative diabetic retinopathy; PDR, proliferative diabetic retinopathy.

noncontact tonometer is very popular and widely used for routine ocular examination and correlates well with the Goldmann applanation tonometer. Thus, we reviewed the IOP data from those patients who were examined routinely with a noncontact tonometer. Our results showed that patients with diabetes mellitus had significantly higher IOP than did nondiabetic patients.

The mechanisms that cause higher IOP in diabetic patients were not determined. An epidemiological study of the association between ocular hypertension and family history of patients with type 2 diabetes mellitus reported that genetic factors may play some role in ocular hypertension. ${ }^{21}$ Another study showed that dysfunction of the autonomic system in diabetic patients might contribute to increased IOP. ${ }^{22}$ It has been suggested that elevated blood glucose levels induces an osmotic gradient with consequent fluid shifts into the intraocular space which elevates the IOP. ${ }^{5}$

In addition, several large population-based cross-sectional studies have documented a significant correlation between elevated blood glucose or $\mathrm{HbA}_{1 \mathrm{c}}$ levels and raised IOP in diabetic patients. ${ }^{2-4,6,10,15}$ We also found that the IOP was significantly correlated with $\mathrm{HbA}_{1 \mathrm{c}}$ in patients with diabetic retinopathy, although the stage of diabetic retinopathy was not associated with IOP. Thus, high glucose in the blood or some aspects of glucose metabolism could affect IOP. Although a mean difference of $1.5 \mathrm{mmHg}$ may not be clinically irrelevant in nonglaucomatous patients, it should be noted that $\mathrm{HbA}_{1 \mathrm{c}}$ levels raise IOP in diabetic patients.

In this study, IOP was not significantly associated with gender in either the diabetic or nondiabetic group, which is in agreement with the results of earlier studies. ${ }^{19}$ Many studies have shown that the IOP increases with age. $3,11,14,19$
However, the recent Beijing ${ }^{9}$ study did not find any significant correlation between IOP and age. Moreover, the Tajimi study ${ }^{16}$ reported a significant negative correlation between age and IOP in the adult Japanese population. Therefore, the relationship between IOP and age is contradictory.

Our finding that the correlation between IOP and age was not significant in nondiabetic patients disagrees with the finding of the Tajimi study, ${ }^{16,17}$ but IOP decreased significantly with increasing age in patients with diabetes. One reason for this discrepancy in nondiabetic patients is that the Tajimi study was population-based, which was not the case in our study. Another reason may be that patients with glaucoma were excluded from our study.

The present study has some limitations. First, measurement of central corneal thickness (CCT) was not carried out. IOP measurement may depend on $\mathrm{CCT},{ }^{23}$ and the CCT of diabetic patients has been reported to be greater when compared with that of nondiabetic patients. ${ }^{24,25}$ Even with use of the noncontact tonometer, the IOP measurement is still affected by $\mathrm{CCT} .{ }^{26}$ Thus, we may be concerned about the influence of a thick CCT on IOP measurement in diabetic patients. IOP is usually examined routinely, but CCT values are not examined routinely, so higher IOP levels in diabetics should be still considerable. In addition, glycation-induced corneal collagen cross-links in diabetes can cause corneal stiffening, ${ }^{27}$ which has also been shown to increase the value of the measured IOP over the true IOP. ${ }^{28,29}$ Further, IOP is at least partly genetically mediated. ${ }^{30}$ We only investigated the Japanese population, so it is possible that data from different genetic populations may yield different statistical results. In addition, this was a retrospective study. However, our results add to the evidence that diabetic patients have significantly higher IOPs, although this study was not designed to determine the mechanism for this relationship.

In conclusion, our findings showed that patients with diabetes mellitus had significantly higher IOP than nondiabetic patients. In addition, there was a significant positive correlation between IOP and $\mathrm{HbA}_{1 \mathrm{c}}$ levels in patients with diabetic retinopathy. These findings indicate that diabetic patients have higher IOP, especially those with poor control of diabetes.

\section{Disclosure}

The authors report no conflicts of interest in this work.

\section{References}

1. King H, Aubert RE, Herman WH. Global burden of diabetes, 1995-2025: prevalence, numerical estimates, and projections. Diabetes Care. 1998;21(9):1414-1431. 
2. Klein BE, Klein R, Jensen SC. Open-angle glaucoma and olderonset diabetes. The Beaver Dam Eye Study. Ophthalmology. 1994;101(7):1173-1177.

3. Klein BE, Klein R, Linton KL. Intraocular pressure in an American community. The Beaver Dam Eye Study. Invest Ophthalmol Vis Sci. 1992;33(7):2224-2228.

4. Dielemans I, de Jong PT, Stolk R, Vingerling JR, Grobbee DE, Hofman A. Primary open-angle glaucoma, intraocular pressure, and diabetes mellitus in the general elderly population. The Rotterdam Study. Ophthalmology. 1996;103(8):1271-1275.

5. Mitchell P, Smith W, Chey T, Wang JJ, Chang A. Open-angle glaucoma and diabetes: The Blue Mountains Eye Study, Australia. Ophthalmology. 1997;104(4):712-718.

6. Chopra V, Varma R, Francis BA, Wu J, Torres M, Azen SP; Los Angeles Latino Eye Study Group. Type 2 diabetes mellitus and the risk of openangle glaucoma the Los Angeles Latino Eye Study. Ophthalmology. 2008;115(2):227-232.

7. Tielsch JM, Katz J, Quigley HA, Javitt JC, Sommer A. Diabetes, intraocular pressure, and primary open-angle glaucoma in the Baltimore Eye Survey. Ophthalmology. 1995;102(1):48-53.

8. Quigley HA, West SK, Rodriguez J, Munoz B, Klein R, Snyder R. The prevalence of glaucoma in a population-based study of Hispanic subjects: Proyecto VER. Arch Ophthalmol. 2001;119(12):1819-1826.

9. Xu L, Wang YX, Jonas JB, Wang YS, Wang S. Ocular hypertension and diabetes mellitus in the Beijing Eye Study. J Glaucoma. 2009;18(1):21-25.

10. Tan GS, Wong TY, Fong CW, Aung T; Singapore Malay Eye Study. Diabetes, metabolic abnormalities, and glaucoma. Arch Ophthalmol. 2009;127(10):1354-1361.

11. Le A, Mukesh BN, McCarty CA, Taylor HR. Risk factors associated with the incidence of open angle glaucoma: the Visual Impairment Project. Invest Ophthalmol Vis Sci. 2003;44(9):3783-3789.

12. Ellis JD, Evans JM, Ruta DA, et al. Glaucoma incidence in an unselected cohort of diabetic patients: is diabetes mellitus a risk factor for glaucoma? DARTS/MEMO collaboration. Diabetes Audit and Research in Tayside Study. Medicines Monitoring Unit. Br J Ophthalmol. 2000;84(11):1218-1224.

13. de Voogd S, Ikram MK, Wolfs RC, et al. Is diabetes mellitus a risk factor for open angle glaucoma? The Rotterdam Study. Ophthalmology. 2006;113(10):1827-1831.

14. Wu SY, Leske MC. Associations with intraocular pressure in the Barbados Eye Study. Arch Ophthalmol. 1997;115(12):1572-1576.

15. Hennis A, Wu SY, Nemesure B, Leske MC; Barbados Eye Studies Group. Hypertension, diabetes, and longitudinal changes in intraocular pressure. Ophthalmology. 2003;110(5):908-914.
16. Kawase K, Tomidokoro A, Araie M, Iwase A, Yamamoto T; Tajimi Study Group; Japan Glaucoma Society. Ocular and systemic factors related to intraocular pressure in Japanese adults: the Tajimi study. Br J Ophthalmol. 2008;92(9):1175-1179.

17. Suzuki Y, Iwase A, Araie M, et al. Risk factors for open-angle glaucoma in a Japanese population: The Tajimi Study. Ophthalmology. 2006;113(9):1613-1617.

18. Wilkinson CP, Ferris FL 3rd, Klein RE, et al; Global Diabetic Retinopathy Project Group. Proposed international clinical diabetic retinopathy and diabetic macular edema disease severity scales. Ophthalmology. 2003;110(9):1677-1682.

19. Quigley HA. Number of people with glaucoma worldwide. $\mathrm{Br} J$ Ophthalmol. 1996;80(5):389-393.

20. Wong TY, Loon SC, Saw SM. The epidemiology of age related eye diseases in Asia. Br J Ophthalmol. 2006;90(4):506-511.

21. Clark CV, Mapstone R. The prevalence of diabetes mellitus in the family history of patients with primary glaucoma. Doc Ophthalmol. 1986;6(2):161-163.

22. Mapstone R, Clark CV. Prevalence of diabetes in glaucoma. Br Med J (Clin Res Ed). 1985;291(6488):93-95.

23. Brandt JD, Beiser JA, Kass MA, Gordon MO. Central corneal thickness in the Ocular Hypertension Treatment Study (OHTS). Ophthalmology 2001;108(10):1779-1788

24. Ozdamar Y, Cankaya B, Ozalp S, Acaroglu G, Karakaya J, Ozkan SS. Is there a correlation between diabetes mellitus and central corneal thickness? J Glaucoma. 2010;19(9):613-616.

25. Oriowo OM. Profile of central corneal thickness in diabetics with and without dry eye in a Saudi population. Optometry. 2009;80(8): $442-446$.

26. Domke N, Hager A, Wiegand W. Intraocular pressure and corneal thickness. A comparison between non-contact tonometry and applanation tonometry. Ophthalmologe. 2006;103(7):583-587. German.

27. Sady C, Khosrof S, Nagaraj R. Advanced Maillard reaction and crosslinking of corneal collagen in diabetes. Biochem Biophys Res Commun. 1995;214(3):793-797.

28. Broman AT, Congdon NG, Bandeen-Roche K, Quigley HA. Influence of corneal structure, corneal responsiveness, and other ocular parameters on tonometric measurement of intraocular pressure. J Glaucoma. 2007;16(7):581-588.

29. Krueger RR, Ramos-Esteban JC. How might corneal elasticity help us understand diabetes and intraocular pressure? J Refract Surg. 2007;23(1):85-88

30. van Koolwijk LM, Ramdas WD, Ikram MK, et al. Common genetic determinants of intraocular pressure and primary open-angle glaucoma. PLoS Genet. 2012;8(5):e1002611. Epub May 3, 2012.
Clinical Ophthalmology

\section{Publish your work in this journal}

Clinical Ophthalmology is an international, peer-reviewed journal covering all subspecialties within ophthalmology. Key topics include: Optometry; Visual science; Pharmacology and drug therapy in eye diseases; Basic Sciences; Primary and Secondary eye care; Patient Safety and Quality of Care Improvements. This journal is indexed on Submit your manuscript here: http://www.dovepress.com/clinical-ophthalmology-journal

\section{Dovepress}

PubMed Central and CAS, and is the official journal of The Society of Clinical Ophthalmology (SCO). The manuscript management system is completely online and includes a very quick and fair peer-review system, which is all easy to use. Visit http://www.dovepress.com/ testimonials.php to read real quotes from published authors. 